\title{
Performance of Water Treatment Techniques on Cocopeat Media Filled Grow Bed Aquaponics System
}

\author{
Mohd Johari Kamauddin ${ }^{1,2 *}$, Nur Syahmi Izzati Ali Othman ${ }^{1,2}$, Muhammad Haafiz Abu \\ Bakar $^{2}$, Anwar Johari ${ }^{1,2}$, and Mimi Haryani Hassim ${ }^{1,2}$ \\ ${ }^{1}$ Centre of Hydrogen Energy, Institue of Future Energy, Universiti Teknologi Malaysia, 81310 Johor \\ Bahru, Malaysia \\ ${ }^{2}$ Department of Chemical Engineering, School of Chemical and Energy Engineering, Universiti \\ Teknologi Malaysia, 81310 Johor Bahru, Malaysia
}

\begin{abstract}
Aquaponics system is an innovative idea which combined both aquaculture and hydroponics systems. In this study performance of four different types of water treatment technique was investigated in cocopeat media filled grow bed aquaponics system. The techniques that had been investigated were mechanical filter, biological filter, combination of both mechanical and biological filters and grow media (cocopeat) itself as filtration media. The effectiveness these techniques were assessed through (i) water quality and nutrients level of circulated water and (ii) growth rates of plant (Gynura procumbens) and Red Nile Tilapia fish (Oreochromis niloticus) The (i) water quality ( $\mathrm{pH}$, temperature, total suspended solid and dissolved oxygen) (ii) nutrient level (ammonia, nitrite, nitrate) and (iii) grow rates of plant and fish were weekly measured for this study. The results revealed that cocopeat media filled grow bed only was insufficient to act as water treatment unit in the aquaponics system studied. The aquaponics system required at least a biological or mechanical filter to produce acceptable yields of fish and plant. For the long term, the combination of axial flow and biofilter with superlative ratio was suggested in order to produce the best performance of parameters studied. This integrated technique was able to maintain the water quality within the tolerance limit of fish besides supplying enough amount nutrients (especially nitrate) for the plant growth and easier maintenance work in terms of cleaning and disposal of sludge.
\end{abstract}

\section{Introduction}

Aquaculture has become one of the fastest-growing food producing sectors since 1980s and accounted for almost half (49\%) of global fish consumption in 2012 and it is estimated that aquaculture would account for $62 \%$ of world's fish supply for human consumption by $2030[1,2]$. The large scale application of aquaculture, however, is restricted by land and water utilization as well as by environmental concerns, thus, aquaponics which is an

*Corresponding author: mjohari@utm.my 
integrated system that links aquaculture and hydroponic production is considered to be an innovative and sustainable solution [3, 4]. Aquaponics system is a promising technology in the integration of fish and hydroponic plant production. The fish water which is rich in nutrients is used for plant growth and the amounts of nutrients produced in a fish culture system depend on the density of fish in the system and the protein content of the fish food [5]. An aquaponics system can be highly successful if it is balanced in terms of nutritional intake and managed correctly [6].

Aquaponics systems have two main components, the grow bed (the hydroponic part of the system) and the fish tank (the aquaculture part of the system). There are three main types of hydroponics systems namely media-filled, floating raft and nutrient film technique. The comparison study of these systems was reviewed and media-filled grow bed was reported to yield higher product for leafy veggies such as lettuce (Lactuca sativa) [6, 7]. The importance of media-filled grows bed lies in its ability to provide plants with a foundation and as an anchor for it to grow. It also serves as a surface area for the nitrifying process to take place and facilitates the filtration of the solid in aquaponics system. Key elements of media-filled grow bed physical properties are its ability to drain nutrient-rich water effectively so plant roots are not waterlogged and it must not contain any contaminants that could affect the water quality.

Several types of media-filled grow bed that are available commercially are Lightweight Expended Clay Aggregate (LECA) and Lava Rock gravel. Other alternative for the mediafilled grow bed is River Gravel which is deprived to retain water, very heavy and has a much lower surface area to support microbial activities and thus lowering its bio-filtration capacity. All these media-filled grow bed except river gravel are not available locally and the price is high per unit volume.

It is the intention of this research work to design and fabricate an aquaponics system compatible with Malaysian urban resident system using locally sourced material as mediafilled grow bed. Several materials have been identified by the authors such as cocopeat, rice husk and mixture of cocopeat and rice husk as cheap viable options. Preliminary study on this area had been carried out recently by the authors. From the study, cocopeat performed as the most recommended media to replace LECA due to its outstanding influence on the growth rates of plant (Gynura procumbens) and red Nile Tilapia fish, water quality and nutrient levels presented in the grow bed media aquaponics system equipped with biofilter. However, the capability of cocopeat itself to act as filtration media that equivalent to LECA is still did not proven and examined yet.

A compact, simple and efficient water treatment unit or grow media self-filtration that involved mechanical and microbial activities is crucial for optimum performance of the cocopeat media filled grow bed aquaponics system. Based on this prospect, the objective of this study is to assess the performance of various types of water treatment technique on the aquaponics system studied. The techniques will be investigate in this study include axial flow (mechanical) filter, biofilter, combination of the both mentioned techniques and grow media itself as a filter.

\section{Methodologies}

The rigs of aquaponics system were built in 20' x 20' greenhouse (nearby Block N11) that located in Universiti Teknologi Malaysia (UTM) Skudai, Johor. The technique used for plant cultivation was media-based technique that using cocopeat as grow media. Four grow bed aquaponics systems with different types of water treatment technique were set-up. System 1 equipped with both mechanical and biological filter in a compact vessel (System 1). Settling tank by axial flow (System 2) was use as the mechanical filter and biological filter (System 3) using bio ball as filtration media. Aquaponics system without water 
treatment unit was used as baseline system (System 4) in this study. In the system 4, the water from the aquaculture tank was directly pumped to the grow bed where the plants growth. Thus, the media (cocopeat) itself and roots of the plants were acted as filtration unit as schematic figured (System B) in Figure 2.1. Three grow bed aquaponic systems with different water treatment techniques were set-up based on schematic diagram (System A) as shown in Figure 2.1. For each aquaponics system there was a hydroponic tank (grower) which consists of 24 polybags filled with cocopeat as grow media and planted with Gynura procumbens as plant. The total volume of water treatment unit installed in aquaponics systems $1-3$ was equally fixed to $\sim 0.12 \mathrm{~m}^{3}$ which is about $25.5 \%$ of water volume in fish tank $\left(0.47 \mathrm{~m}^{3}\right)$. The schematic diagram of each water treatment unit used in this study is shown in Figure 2.2.

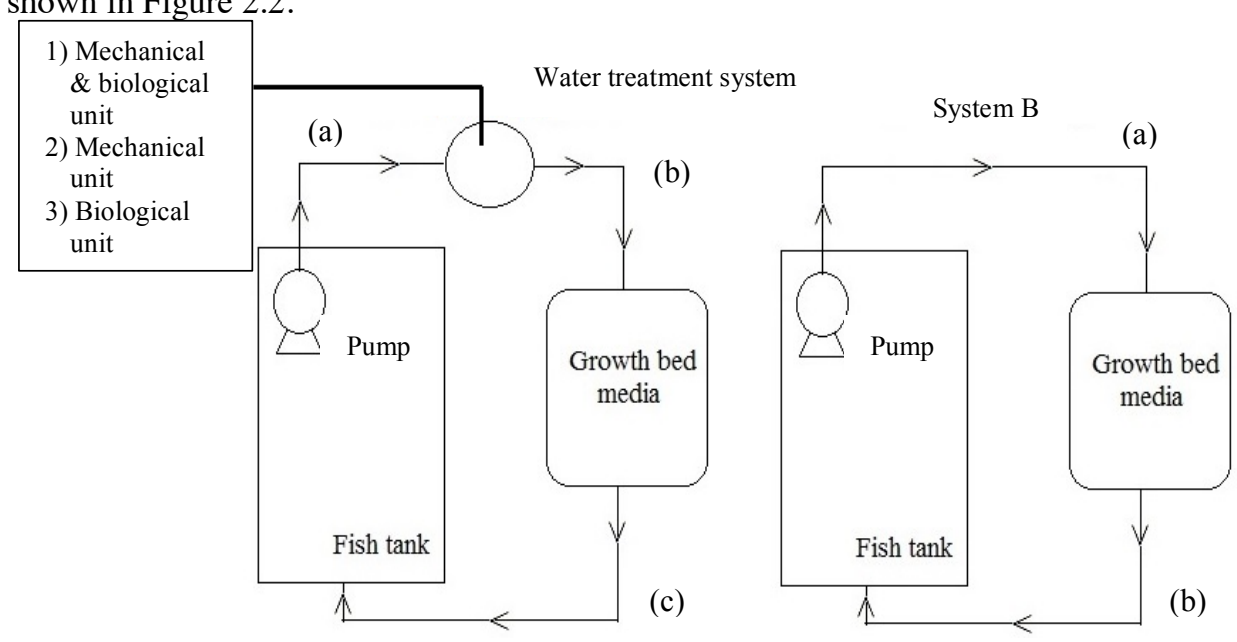

Fig. 2.1 Schematic diagrams of installation water filtration techniques and water sampling points in grow bed aquaponic systems.

In order to quantify the performance of water treatment units installed, the data collection of water quality and nutrient levels for the aquaponics systems were carried out for twelve weeks. The water quality parameters studied were $\mathrm{pH}$, temperature, total suspended solid (TSS) and dissolved oxygen (DO). The water $\mathrm{pH}$ level was measured using bench top $\mathrm{pH}$ meter [8]. Temperature of water was measured in-situ using thermometer. In addition, the measured parameters for nutrient levels were ammonia, nitrite and nitrate concentrations by using the HI 83099 COD and Multi-parameter Bench Photometer [9]. These analyses of water were measured from the specific sampling points $(a, b$ and $c$ ) for each aquaponics system as shown in Figure 2.1.

The sampling point ' $a$ ' indicated the water sample from the fish tank; point ' $b$ ' was the effluent of water treatment unit (threated water) while point 'c' was outlet flow of the hydroponic tank (grower). The analyses were carried out weekly at Environmental Engineering Laboratory (Block N13) in UTM. Besides, the growth rate of red Nile Tilapia fish, Oreochromis niloticus was determined based on fish's weight. Meanwhile height and weight were measured for plant growth rate and yield of Gynura procumbens respectively. All the performance parameters studied in this research were summarised in Table 2.1. 

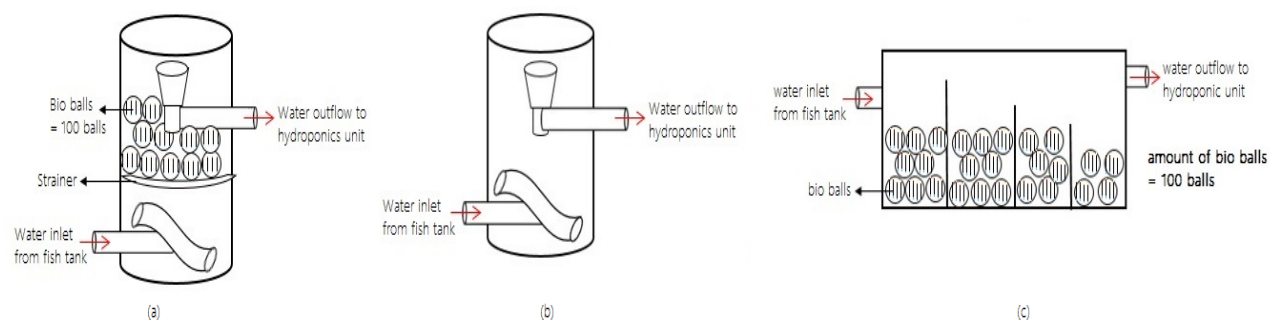

Figure 2.2 Design diagram of each water treatment unit installed in the grow media aquaponics system

Figure 2.2 shows the different types of filtration system which were used for the aquaponics system. Figure 2.2 (a) is the combination filtration system of mechanical and biological for the System 1. Meanwhile Figure 2.2 (b) is the mechanical filtration unit by using setting tank as for water treatment in System 2. Besides that, the Figure 2.2(c) is the biological filtration unit by using bio ring and sponge to treat the water in System 3. System 4 did not have any extra filtration unit since System 4 used media to treat the water through the aquaponics system.

Table 2.1 The performance parameters investigated in cocopeat media filled grow bed aquaponics system

\begin{tabular}{|c|c|c|}
\hline Performance Parameter & Measuring Point & $\begin{array}{c}\text { Frequency of data } \\
\text { collection }\end{array}$ \\
\hline Average weight of fish $(\mathrm{kg})$ & \multirow{5}{*}{$\begin{array}{c}\text { Fish in fish tank of the } \\
\text { aquaponic systems } \\
(1,2,3,4)\end{array}$} & \multirow{2}{*}{ Once a week } \\
\hline Weight Gain Percentage $(\%)$ & & \\
\hline Specific Growth Rate, SGR (\% per day) & & \multirow{3}{*}{ At the end of research } \\
\hline Food Conversion Ratio, FCR & & \\
\hline Survival Rate $(\%)$ & & \\
\hline Height of plant (mm) & \multirow{2}{*}{$\begin{array}{c}\text { Plant in the grower bed } \\
\text { of the aquaponic } \\
\text { systems } \\
(1,2,3,4)\end{array}$} & Once a week \\
\hline Yields of plant $(\mathrm{kg})$ & & At the end of research \\
\hline $\mathrm{pH}$ & \multirow{7}{*}{$\begin{array}{l}\text { Water sample collected } \\
\text { from sampling points of } \\
\text { each aquaponics system } \\
(1 \mathrm{a}, 1 \mathrm{~b}, 1 \mathrm{c}, 2 \mathrm{a}, 2 \mathrm{~b}, 2 \mathrm{c} \\
3 \mathrm{a}, 3 \mathrm{~b}, 3 \mathrm{c}, 4 \mathrm{a}, 4 \mathrm{c})\end{array}$} & \multirow{4}{*}{ Once a week } \\
\hline Temperature of Water $\left({ }^{0} \mathrm{C}\right)$ & & \\
\hline Dissolved Oxygen, DO (mg/L) & & \\
\hline Total Suspended Solids, TSS (mg/L) & & \\
\hline Ammonia $(\mathrm{mg} / \mathrm{L})$ & & \multirow{3}{*}{ Once a week } \\
\hline Nitrite $(\mathrm{mg} / \mathrm{L})$ & & \\
\hline Nitrate $(\mathrm{mg} / \mathrm{L})$ & & \\
\hline
\end{tabular}

\section{Results and Discussion}

Table 3.1 shows the results of water quality based on water sampling points for twelve weeks of the study. From Table 3.1, it can be summarized that the $\mathrm{pH}$ and temperature values of water at all the eleven different water sampling points were well maintained within the desired range, which were from $\mathrm{pH} 6.00$ to 8.50 and temperature of $18^{\circ} \mathrm{C}$ to $30^{\circ} \mathrm{C}$ [10]. Water temperatures of all aquaponics systems were well controlled and maintained is due to nature of aquaponics system where water continuously recirculating (pumping) and all the rigs located in greenhouse with 50\% sunlight shading using orchid nettings. It is important to maintain the level of $\mathrm{pH}$ and temperature throughout the system 
since high value of $\mathrm{pH}$ and temperature could make the ammonia became more toxic which was endangering to the tilapia fish in the aquaponics systems.

The DO in the aquaponics systems was supplied by using air pump (RS-16000) with pump maximum flow rate $(\sim 70 \mathrm{~L} / \mathrm{min})$ that connected through the air tubes and the immersed air stones for each sampling points. The tolerance value for DO in aquaponics system must be higher than $3.0 \mathrm{mg} / \mathrm{L}$ [11]. The values of DO for the all sampling points were higher than $5.0 \mathrm{mg} / \mathrm{L}$ with the lowest values for each system was occurred at fish tank. This is a normal observation due to oxygen consumption by the fish for the respiration process. .

Aquaponics systems 1, 2, and 3 were found to be the lower value in TSS compared to the system 4 . Water quality of fish tank in baseline system (4a) produced the highest value of TSS which followed by 3a, $2 \mathrm{a}$ and $1 \mathrm{a}$ with $11 \mathrm{mg} / \mathrm{L}, 9 \mathrm{mg} / \mathrm{L}, 9 \mathrm{mg} / \mathrm{L}$ and $8 \mathrm{mg} / \mathrm{L}$ respectively. This situation occurred due the absence of water treatment unit in system 4 , hence the suspended particles produced by the fish faeces and wash out cocopeat from the grow bed were circulated in the fish tank. Similar observation was noted by the [12]. All the filtration techniques studied gave the level of TSS in range $2-3 \mathrm{mg} / \mathrm{L}$ for the treated water. This suggests that, mechanical, biological and combination of mechanical and biological filtration units were able to remove suspended solid effectively in cocopeat media filled aquaponics system.

Table 3.1 Average values of water quality measured at specific sampling points in the aquaponic systems.

\begin{tabular}{|l|c|c|c|c|c|c|c|c|c|c|c|}
\hline \multirow{3}{*}{ Parameter } & \multicolumn{10}{|c|}{ Water Sampling Points } \\
\cline { 2 - 12 } & $\mathbf{1 a}$ & $\mathbf{1 b}$ & $\mathbf{1 c}$ & $\mathbf{2 a}$ & $\mathbf{2 b}$ & $\mathbf{2 c}$ & $\mathbf{3 a}$ & $\mathbf{3 b}$ & $\mathbf{3 c}$ & $\mathbf{4 a}$ & $\mathbf{4 c}$ \\
\hline & 6.68 & 6.79 & 6.71 & 6.78 & 6.90 & 6.89 & 7.02 & 7.11 & 6.63 & 6.86 & 6.82 \\
$\mathbf{p H}$ & \pm & \pm & \pm & \pm & \pm & \pm & \pm & \pm & \pm & \pm & \pm \\
& 0.07 & 0.06 & 0.06 & 0.06 & 0.04 & 0.13 & 0.04 & 0.03 & 0.04 & 0.01 & 0.03 \\
\hline Temperature & 28.0 & 28.0 & 28.5 & 28.0 & 28.0 & 28.5 & 28.0 & 28.0 & 28.5 & 28.0 & 28.5 \\
$\left({ }^{\circ} \mathbf{C}\right)$ & \pm & \pm & \pm & \pm & \pm & \pm & \pm & \pm & \pm & \pm & \pm \\
\hline Dissolved & 0.0 & 0.0 & 0.0 & 0.0 & 0.0 & 0.0 & 0.0 & 0.0 & 0.0 & 0.0 & 0.0 \\
Oxygen & 6.17 & 6.73 & 7.00 & 6.57 & 6.71 & 7.85 & 5.17 & 5.62 & 7.02 & 5.88 & 6.77 \\
$(\mathbf{m g} / \mathbf{L})$ & \pm & \pm & \pm & \pm & \pm & \pm & \pm & \pm & \pm & \pm & \pm \\
\hline Total & 0.06 & 0.07 & 0.08 & 0.07 & 0.04 & 0.10 & 0.05 & 0.12 & 0.09 & 0.09 & 0.09 \\
Suspended & $8 \pm$ & $3 \pm$ & $5 \pm$ & $9 \pm$ & $2 \pm$ & $5 \pm$ & $9 \pm$ & $2 \pm$ & $4 \pm$ & $11 \pm$ & $6 \pm$ \\
Solid (mg/L) & 0.8 & 0.5 & 0.5 & 1.1 & 0.5 & 0.8 & 1.2 & 0.5 & 0.5 & 0.9 & 0.9 \\
\hline
\end{tabular}

Table 3.2 shows the concentration of ammonia, nitrite and nitrate data for the aquaponic systems with four different water treatment techniques used. From Table 3.2, it can be obviously seen that the aquaponics systems 1,2 and 3 had the lower values of ammonia compared to the System 4. A detail analysis of ammonia data for all of the water treatment techniques discovered that aquaponics System 3 produced the highest percentage of ammonia removal about $72 \%$, where $\sim 51 \%$ contributed by the water treatment unit installed and the rest of ammonia removal assisted by the grow bed media (cocopeat). This followed by the aquaponics systems 1, 2 and 4 with percentage ammonia removal $44 \%, 37 \%$ and $24 \%$ respectively. However the concentration of ammonia in the fish tank of the aquaponics System 1 was lowest level compared to the others. Integration of axial flow with biofilter in a compact vessel in the aquaponics System 1, help this water treatment unit to firstly residue the large particles of fish faeces (source of ammonia) at the bottom of tank and reduce the total amount of ammonia available in the biofilter section (upper part of the vessel) to oxidise into forms of nitrite and nitrate by the nitrifying bacteria. The sediment at 
the bottom of the water treatment unit will be weekly removed as sludge that can be used as organic fertiliser after treated through composting process or add back to the aquaponics system as plant nutrients after mineralisation proses by the heterotrophic bacteria $[13,14]$. In addition, similar procedure of sludge removal was applied to the mechanical filter in the System 2. These results show that the combination of axial flow and biofilter in a compact water treatment unit is able to produce an efficient filtration system for an aquaponics system in order to control levels of ammonia, TSS and $\mathrm{pH}$. Furthermore, the compact water treatment unit can minimize the using of space especially for urban resident which is their available farming area is limited.

Table 3.2 Average values of nutrient concentrations measured at specific sampling points in the aquaponics systems.

\begin{tabular}{|l|c|c|c|c|c|c|c|c|c|c|c|}
\hline \multirow{3}{*}{ Parameter } & \multicolumn{10}{|c|}{ Water sampling Points } \\
\cline { 2 - 12 } & $\mathbf{1 a}$ & $\mathbf{1 b}$ & $\mathbf{1 c}$ & $\mathbf{2 a}$ & $\mathbf{2 b}$ & $\mathbf{2 c}$ & $\mathbf{3 a}$ & $\mathbf{3 b}$ & $\mathbf{3 c}$ & $\mathbf{4 a}$ & $\mathbf{4 c}$ \\
\hline \multirow{2}{*}{ Ammonia } & 0.25 & 0.18 & 0.14 & 0.35 & 0.26 & 0.22 & 0.39 & 0.19 & 0.11 & 0.42 & 0.32 \\
$(\mathbf{m g} / \mathbf{L})$ & \pm & \pm & \pm & \pm & \pm & \pm & \pm & \pm & \pm & \pm & \pm \\
& 0.02 & 0.02 & 0.04 & 0.02 & 0.05 & 0.06 & 0.03 & 0.03 & 0.02 & 0.02 & 0.03 \\
\hline Nitrite & 0.12 & 0.07 & 0.01 & 0.16 & 0.07 & 0.02 & 0.32 & 0.14 & 0.06 & 0.14 & 0.04 \\
$(\mathbf{m g} / \mathbf{L})$ & \pm & \pm & \pm & \pm & \pm & \pm & \pm & \pm & \pm & \pm & \pm \\
& 0.01 & 0.01 & 0.01 & 0.02 & 0.01 & 0.01 & 0.01 & 0.02 & 0.02 & 0.02 & 0.01 \\
\hline Nitrate & 12.47 & 21.40 & 16.21 & 13.46 & 24.39 & 16.84 & 13.72 & 22.91 & 16.91 & 13.41 & 17.09 \\
$(\mathbf{m g} / \mathbf{L})$ & \pm & \pm & \pm & \pm & \pm & \pm & \pm & \pm & \pm & \pm & \pm \\
& 0.27 & 0.24 & 0.29 & 0.34 & 0.30 & 0.29 & 0.40 & 0.25 & 0.23 & 0.19 & 0.31 \\
\hline
\end{tabular}

Nitrite as an intermediate product of nitrification process of ammonia is required to maintain below its tolerance limit which is about $1.00 \mathrm{mg} / \mathrm{L} \mathrm{[15]} \mathrm{for} \mathrm{a} \mathrm{healthy} \mathrm{aquaponics}$ system. Table 3.2 shows that the highest average value of nitrite in all sampling points is $0.32 \mathrm{mg} / \mathrm{L}$ at location $3 \mathrm{a}$. Thus, all the aquaponics systems were successfully maintained the level of nitrite which is lower than the tolerance limit. Water treatment systems consist of single filtration system of the mechanical filter (System 2) and the biofilter (Systems 3) produced the highest percentage of nitrite removal $\sim 56 \%$ compare to the combination of axial flow and biofilter (System 1) which is $\sim 42 \%$ only. However, if the levels of nitrite exceed the tolerance limit, the problem can be overcome by supplying more oxygen to aquaponics system especially the water treatment unit [15].

Nitrate is the main nutrients for the growth of the Gynura procumbens plants in the aquaponics systems studied. Production of nitrate is directly related to nitrification process where the nitrate is the end product of the process. The results observation from Table 3.2 shows that the concentration of nitrate in fish tanks water for all the aquaponic systems was in range of $12.47-13.72 \mathrm{mg} / \mathrm{L}$. Due to nitrification process of ammonia in water treatment units installed, the concentration of nitrate in effluent of water treatment units was significantly higher than the fish tanks water.

The aquaponics with mechanical filter unit (System 2) produced the highest percentage of nitrate generation which is about $81 \%$ followed by the Systems 1 and 3 with $\sim 72 \%$ and $\sim 67 \%$ respectively. Further analysis of the nitrate concentration in Table 3.2 indicates that the plants absorption of nitrate was directly related with the concentration of nitrate produced by the water treatment units. Hence, aquaponics System 2 notified the highest percentage of nitrate absorption with $\sim 31 \%$. Meanwhile, about $\sim 24-26 \%$ of nitrate absorption was recorded for the Systems 1 and 3.

In addition, System 4 without water treatment unit shows an increment in concentration of nitrate after the grow bed compare to fish tank. Hence, the generation and consumption of nitrate occurred in situ at the grow bed media (cocopeat). However, the exactly amount of nitrate absorption in System 4 cannot be determined. The System 2 with mechanical 
filter produced the highest nitrate generation and absorption in grow bed media (cocopeat). Consequently, with high colonizes of the bacteria and concentration of ammonia $(0.35$ $\mathrm{mg} / \mathrm{L}$ ) may lead to the high rate of nitrification process. In other word, the cocopeat used provided surface area for the nitrification bacteria to growth and mostly nitrification process occurred in-situ in the grow bed media due to absence of filtration media in the mechanical filter. These results of nitrate's generation and intake will be reflected on growth rate of Gynura procumbens in aquaponics system studied, where the System 2 will be expected to produce the highest growth rate and yields.

The growth of plants and fishes were determined through their height and weight respectively. The survival rate and weight gain percentage of the fishes were considered in these experiments. Initially each aquaponics system consists of hydroponic tank that planted with 24 Gynura procumbens plants (in polybags) and 25 red Nile Tilapia, Oreochromis niloticus fishes were released in fish tank. The purpose of using polybags (24 units with size $13 \times 13 \mathrm{~cm}$ ) in hydroponics tank is to hold the grow bed media (cocopeat) from flow with water and minimize the quantity of media used. Table 3.3 shows the growth rate of Tilapia fish in four aquaponic systems for twelve weeks period of study.

Table 3.3 Growth performances of red Nile tilapia, Oreochromis niloticus fish.

\begin{tabular}{|c|c|c|c|c|c|c|c|c|}
\hline \multirow{3}{*}{ Parameter } & \multicolumn{8}{|c|}{ Aquaponics } \\
\hline & \multicolumn{2}{|c|}{ System 1} & \multicolumn{2}{|c|}{ System 2} & \multicolumn{2}{|c|}{ System 3} & \multicolumn{2}{|c|}{ System 4} \\
\hline & $\begin{array}{c}\text { Week } \\
\text { 0 }\end{array}$ & $\begin{array}{c}\text { Week } \\
12\end{array}$ & $\begin{array}{c}\text { Week } \\
0\end{array}$ & $\begin{array}{c}\text { Week } \\
12\end{array}$ & $\begin{array}{c}\text { Week } \\
\text { 0 }\end{array}$ & $\begin{array}{c}\text { Week } \\
12\end{array}$ & $\begin{array}{c}\text { Week } \\
\text { 0 }\end{array}$ & $\begin{array}{c}\text { Week } \\
12\end{array}$ \\
\hline $\begin{array}{l}\text { Average Weight (g) } \\
\text { per fish }\end{array}$ & 70.0 & 238.6 & 69.3 & 240.4 & 70.6 & 248.4 & 68.5 & 236.3 \\
\hline $\begin{array}{l}\text { Weight gain } \\
\text { percentage }(\%)\end{array}$ & \multicolumn{2}{|c|}{241} & \multicolumn{2}{|c|}{247} & \multicolumn{2}{|c|}{252} & \multicolumn{2}{|c|}{245} \\
\hline $\begin{array}{l}\text { Specific growth } \\
\text { rate, SGR (\% per } \\
\text { day) }\end{array}$ & \multicolumn{2}{|c|}{2.87} & \multicolumn{2}{|c|}{2.94} & \multicolumn{2}{|c|}{3.00} & \multicolumn{2}{|c|}{2.92} \\
\hline $\begin{array}{l}\text { Food conversion } \\
\text { ratio, FCR }\end{array}$ & \multicolumn{2}{|c|}{1.24} & \multicolumn{2}{|c|}{1.22} & \multicolumn{2}{|c|}{1.17} & \multicolumn{2}{|c|}{1.24} \\
\hline Survival rate (\%) & \multicolumn{2}{|c|}{92.00} & \multicolumn{2}{|c|}{88.00} & \multicolumn{2}{|c|}{96.00} & \multicolumn{2}{|c|}{88.00} \\
\hline
\end{tabular}

Based on Table 3.3, the aquaponic grow media systems 1, 2, 3, and 4 produced weight gain percentage of $241 \%, 247 \%, 252 \%$ and $245 \%$ respectively. Thus, aquaponics System 3 gave the highest weight gain percentage of Tilapia fish's. In term of specific growth rate (SGR), System 3 produced the highest SGR of fish compared to the other systems. The SGR for System 1, 2 and 4 were 2.87, 2.94 and $2.92 \%$ per day. In addition, the values of FCR for System 1, 2, 3 and 4 were 1.24, 1.22, 1.17, and 1.24 respectively. The value of FCR for the System 3 was the lowest among four aquaponics systems, hence that indicates a better conversion of feed given to growth of Tilapia fish. Furthermore, Table 3.3 indicates that the survival rate percentage of Tilapia fish in System 3 was the highest among all systems which is $\sim 96 \%$. Meanwhile, the aquaponics system without a water treatment unit (System 4 ) only achieved $\sim 84 \%$ of the survival rate.

By relate this observation with previous results in Tables 3.1 and 3.2; these results proved that the water treatment unit which is able to maintain a lower level of ammonia and of TSS with stable $\mathrm{pH}$ and temperature is the best and crucial for the growth of Tilapia fish in an aquaponics system.

Table 3.4 tabulates the average percentage growth and yield of 24 Gynura procumbens plants in each grow media of the aquaponics system for the 12 weeks of study. From Table 
3.4, the weight of plants for System 1,2, 3 and 4 were 5.02, 5.29, 4.54 and $3.66 \mathrm{~kg}$ respectively. The highest percentage growth based on height of plant (346\%) and yield $(5.29 \mathrm{~kg})$ was produced by aquaponics System 2 as expected in previous discussion. This is due to capability of water treatment unit (mechanical filter) installed to generate the highest nitrate concentration as formerly mentioned. Meanwhile aquaponics System 4 without water treatment unit produced the lowest percentage of plant growth $(\sim 200 \%)$ among the four systems. This is due to the inefficient nitrification process in the system, which is generated the lowest nitrate concentration that the main nutrient for plants to growth in an aquaponics system. Moreover, the roots of the plants in the System 4 were covered by algae. Thus, there may have a potential on disruption of nitrate absorption process by the roots of the plants.

System 1 (combination of axial flow and biological filter) and System 3 (biological filter) as water treatment units produced the moderate results on percentage of yield with $\sim 5 \%$ and $\sim 14 \%$ lower compared to the System 2 respectively. This is related to percentage of nitrate generated by the water treatment units installed which is about $\sim 67-72 \%$ compared to $\sim 81 \%$ produced by mechanical filter.

Table 3.4 Growth performances of longevity spinach, Gynura procumbens plants.

\begin{tabular}{|l|c|c|c|c|c|c|c|c|}
\hline \multirow{2}{*}{ Parameter } & \multicolumn{9}{|c|}{ Aquaponics } \\
\cline { 2 - 9 } & \multicolumn{2}{|c|}{ System 1 } & \multicolumn{2}{c|}{ System 2 } & \multicolumn{2}{c|}{ System 3 } & \multicolumn{2}{c|}{ System 4 } \\
\cline { 2 - 9 } & $\begin{array}{c}\text { Week } \\
\mathbf{0}\end{array}$ & $\begin{array}{c}\text { Week } \\
\mathbf{1 2}\end{array}$ & $\begin{array}{c}\text { Week } \\
\mathbf{0}\end{array}$ & $\begin{array}{c}\text { Week } \\
\mathbf{1 2}\end{array}$ & $\begin{array}{c}\text { Week } \\
\mathbf{0}\end{array}$ & $\begin{array}{c}\text { Week } \\
\mathbf{1 2}\end{array}$ & $\begin{array}{c}\text { Week } \\
\mathbf{0}\end{array}$ & $\begin{array}{c}\text { Week } \\
\mathbf{1 2}\end{array}$ \\
\hline Average height (cm) & 15.9 & 50.6 & 16.3 & 72.7 & 16.5 & 66.8 & 16.7 & 50.00 \\
\hline $\begin{array}{l}\text { Percentage of } \\
\text { growth (\%) }\end{array}$ & \multicolumn{2}{|c|}{218} & \multicolumn{2}{|c|}{346} & \multicolumn{2}{|c|}{305} & \multicolumn{2}{c|}{200} \\
\hline Yield (kg) & - & 5.02 & - & 5.29 & - & 4.54 & - & 3.66 \\
\hline
\end{tabular}

\section{Conclusions}

In order to get a comprehensive view on how the water treatment technique affected performance of a growth bed media (cocopeat) aquaponics system, four types of water treatment technique were studied. The techniques include axial flow, biofilter, combination of axial flow and biofilter in a compact vessel and grow media itself as filter. Water quality, nutrients concentrations, growth rate and yield of Tilapia fish and Gynura procumbens plant were measured as performance of the aquaponics system. Based on 12 weeks of collected data, the results notified that the cocopeat as grow media in an aquaponics system itself was insufficient to act as filtration and nitrifying media, hence produced the lowest performance in most parameters measured. The aquaponics system based on biological filter (System 1 and 3) produced the best performance on water quality (pH, TSS and ammonia) and growth rate of Tilapia fish together with moderate results in growth rate and yield of plant. Meanwhile, the aquaponics system with mechanical filter produced the highest growth rate and yield of plant and adequate quality of water and growth rate. In addition, the system with mechanical filter such as in aquaponics System 1 and 3 provides advantage in routinely maintenance related to sludge disposal. With consideration of maintenance works involved and long run performance, these results suggested that combination of mechanical and biological filters with superlative ratio is required for the optimum performance of cocopeat media filled grow bed aquaponics system. 


\section{Recommendations}

For further research, the effect of volume ratio of the water treatment unit to the fish tank water should be considered. In addition, the volume ratio between the axial flow and the biofilter together with the hydraulic retention time of water treatment system are worth to examine in order to produce an efficient water treatment unit. Consequently the optimize performance of grow bed media (cocopeat) aquaponics system in term of water quality, growth rate and yield of aquaculture and plant products can be achieved.

The research for this paper was financially supported by the Universiti Teknologi Malaysia (UTM), Ministry of Education (MOE) and University Grants (TDR), VOT No. 06G46 for research activity..

\section{References}

1. C. Somerville, M. Cohen, E. Pantanella, A. Stankus, A. Lovatelli, Small-scale aquaponic food production. FAO Fisheries and Aquaculture (2014)

2. Y. Zou, Z. Hu, J. Zhang, C. Guimbaud, Q. Wang, Y. Fang, Effect of seasonal variation on nitrogen transformations in aquaponics of northern China. Ecological Engineering, 94, 30-36 (2016)

3. Z. Hu, J. Li, K. Chandran, S. Kim, C. S. Tamaru, S. K. Khanal, Nitrogen Transformations in Aquaponic System (2015)

4. R. V. Tyson, M. D. Danyluk, E. H. Simonne, D. D. Treadwell, Aquaponics sustainable vegetable and fish co-production. Proceedings of the Florida State Horticultural Society, 125, 381-385 (2012)

5. A. Endut, A. Jusoh, N. Ali, W. B. Wan Nik, A. Hassan, A study on the optimal hydraulic loading rate and plant ratios in recirculation aquaponic system. Bioresource Technology, 101(5), 1511-1517 (2010)

6. A. Shete, A. Verma, N. Chadha, C. Prakash, R. M. Peter, I. Ahmad, T. Nuwansi, Optimization of hydraulic loading rate in aquaponic system with Common carp (Cyprinus carpio) and Mint (Mentha arvensis). Aquacultural Engineering, 72(10) (2016)

7. W. A. Lennard, B. V. Leonard, A comparison of three different hydroponic subsystems (gravel bed, floating and nutrient film technique) in an Aquaponic test system. Aquaculture International, 14(6), 539-550 (2006)

8. O. Grunert, D. Reheul, M. van Labeke, M. Perneel, E. Hernandez-Sanabria, S. E. Vlaeminck, N. Boon, Growing Media Constituents Determine the Microbial Nitrogen Conversions in Organic Growing Media for Horticulture. Mircobial Biotechnology, 9(3), 389-399 (2016)

9. Hanna Instruments Inc. HI 83099 Photometer COD and Multiparameter Bench Photometer, 1-69 (2012)

10. M. Stout, The Complete Idiot's Guide to Aquaponic Gardening (2013)

11. K. Connolly, T. Trebic, Optimization of a Backyard Aquaponic Food Production System. Bioresource Engineering, 1-74 (2010)

12. A. Masłoń, J. A. Tomaszek, A study on the use of the Bio Ball as a biofilm carrier in a sequencing batch reactor. Bioresource Technology, 196, 577-585 (2015) 
13. V. Nozzi, A. Graber, Z. Schmautz, A. Mathis, R. Junge, Nutrient Management in Aquaponics: Comparison of Three Approaches for Cultivating Lettuce, Mint and Mushroom Herb. Agronomy, 8(27), 1-15 (2018)

14. R. I. Thorarinsdottir, Aquaponics Guidelines (2015)

15. H. Yavuzcan Yildiz, L. Robaina, J. Pirhonen, E. Mente, D. Domínguez, G. Parisi, Fish Welfare in Aquaponic Systems: Its Relation to Water Quality with an Emphasis on Feed and Faeces-A Review. Water (2017) 